\title{
Avaliação do sistema de controle gerencial de uma empresa do setor químico: um estudo de caso
}

Evaluation of the management control system of a company of chemical sector: a case study

\section{Valter da Silva Faia}

Mestrando em Administração pela Universidade Estadual de Maringá

Professor Auxiliar do Departamento de Ciências Contábeis da Universidade Estadual de Maringá

Endereço: Avenida Colombo, nº 5.790, Jardim Universitário, Bloco C23, Sala 239.

CEP: 87020-900 - Maringá/PR - Brasil

E-mail: valterfaia@gmail.com

Telefone: (44) 9945-4156

\section{Joatan Bitencourt Milan}

Especialista em Contabilidade e Controladoria pela Universidade Estadual de Maringá

Contador na empresa Segura Transporte e Logística Ltda.

Endereço: Avenida Brasil, no 284, sala 01, Vila Operária

CEP: 87050-000 - Maringá/PR - Brasil

E-mail: john_milan_85@hotmail.com

Telefone: (44) 9825-4477

\section{Josir Simeone Gomes}

Doutor em Administração pela COPPEAD/ Universidade Federal do Rio de Janeiro Pós-Doutorado pela Universidad Carlos III de Madrid

Professor Adjunto-Doutor no Programa de Doutorado e Mestrado em Administração na Universidade Unigranrio

Endereço: Travessa Visconde de Moraes, $\mathrm{n}^{\circ} 199$

CEP: 22260-080 - Rio de Janeiro/RJ - Brasil

E.mail: josirgomes@superig.com.br

Telefone: (21) 9871-7850 e 3579-6351

Artigo recebido em 26/03/2012. Revisado por pares em 07/05/2012. Reformulado em 13/12/2012. Recomendado para publicação em 13/02/2013 por Sandra Rolim Ensslin (Editora Científica). Publicado em 30/04/2013. 


\title{
Resumo
}

Segundo Berry et al. (2009), os desafios para o projeto de sistemas de controle gerencial destacam a importância de se considerarem as variáveis contexto social e cultura organizacional, assim como as medidas de natureza não financeira. $O$ presente trabalho objetivou avaliar o sistema de controle de gestão da empresa de pequeno porte HK Química, confrontando a teoria com a prática por meio de estudo de caso. A coleta de dados constou da realização de entrevistas e por observação ativa. Os resultados evidenciam um sistema de controle de gestão organizacional bastante afastado do referencial teórico, concentrado somente em medidas financeiras.

Palavras-chave: Sistema de Controle Gerencial. Contabilidade. Administração.

\begin{abstract}
According to Berry et al. (2009), the challenges for the design of management control systems highlight the importance of considering the social context and organizational culture, as well as non-financial measures. The present study aimed to assess the management control system of the small company HK chemistry, confronting the theory with the practice through the case study method. Data collection consisted of conducting interviews and active observation. The results show an organizational management control system quite away from the theoretical framework, focused only on financial measures.
\end{abstract}

Keywords: Management Control System. Accounting. Administration.

\section{Introdução}

A complexidade do ambiente no qual as organizações estão inseridas tem exercido influência direta no processo de gestão organizacional, uma vez que o desafio da continuidade e o cumprimento dos objetivos organizacionais têm se tornado cada vez mais difícil. Cabe aos gestores definir quais processos ou atividades agregam valor à empresa e aos stakeholders, criando alternativas para conduzir a organização para os resultados desejados.

Entre os desafios do processo de gestão que compreende as atividades de planejamento, execução e controle, tem-se a adoção de um sistema de controle da gestão que permite à organização avaliar seu desempenho, motivar pessoas e antecipar tendências que possam ser interessantes para a empresa. Portanto, deve-se adotar uma estrutura de controle gerencial que cumpra seu papel organizacional de direcionar seus gestores no sentido das estratégias adotadas (AGUIAR; PACE; FREZATTI, 2009).

Esse desafio é inerente a toda organização, entretanto apresenta características diferentes em virtude das variações na dimensão e do ambiente enfrentado por cada uma delas. Diversos estudos têm abordado o tema de sistema de controle gerencial, especialmente em organizações de porte maior ou em processo de internacionalização (BERRY et al. 2009; CHENHAL, 2003; ANTHONY; GOVINDARAJAN, 2008; FLORENTINO; GOMES, 2009; 
AGUIAR; PACE;FREZATTI, 2009; OYADOMARI et al., 2011; SILVA; FONSECA, 2009; FERREIRA; OTLEY, 2005; HERATH, 2007; RODRIGUES; GOMES; 2006).

Entretanto destaca-se uma lacuna de estudos sobre o tema em organizações de porte menores que possuem grande destaque na economia nacional. Segundo dados do Anuário do Trabalho na Micro e Pequena Empresa 2010 e 2011, publicado pelo SEBRAE e pelo DIEESE (2011), as micro e pequenas empresas (MPEs) foram responsáveis por 48,4\% do total de empregos formais gerados nos estabelecimentos privados não agrícolas brasileiros de 2000 a 2010. No ano de 2010, as MPEs representaram 99\% dos estabelecimentos, 51,6\% dos empregos formais privados não agrícolas e aproximadamente $40 \%$ da massa de salários.

Com base na importância da análise do sistema de controle de gestão das MPEs, o estudo objetiva avaliar este sistema utilizado por uma empresa de pequeno porte do setor químico da cidade de Maringá, Paraná, à luz da literatura, verificando os indicadores utilizados e fundamentados na análise do contexto social e organizacional, bem como da estrutura e dos processos de controle de gestão.

Assim, espera-se avaliar as características do sistema de controle gerencial, evidenciando os fatores determinantes para sua adoção. Portanto serão observados os impactos referentes aos ambientes interno e externo nos quais a organização está inserida, bem como as práticas de gestão adotadas, entre elas está: sistema de informação, sistema de medição e avaliação de desempenho, sistema de incentivo, planejamento e formulação de objetivos e processo orçamentário.

A justificativa, com base no referencial teórico utilizado para a realização deste trabalho, reside no aumento do estoque de conhecimento sobre sistemas de controle em empresas de pequeno porte da região Sul do Brasil que são muito pouco referenciadas na literatura. Para isso, o presente trabalho está organizado com a introdução do tema, uma revisão bibliográfica feita em estudos e publicações relacionados ao tema que subsidiará a análise do caso, a descrição dos procedimentos metodológicos, a apresentação e a análise do caso e, por fim, as considerações finais e recomendações.

\section{Revisão da Literatura}

\subsection{Controle Gerencial}

Ao se estudar a evolução da literatura sobre controle de gestão, pode-se perceber que, embora existam indícios de utilização de conceitos relacionados a planejamento e controle muitos séculos antes da era cristã, como, por exemplo, o livro sobre estratégia militar A Arte da Guerra (The Art of War), escrito pelo general chinês Sun Tzu, no sexto século a.C. É somente a partir de fins do século XV, com o surgimento do Método das Partidas Dobradas, em 1494, de autoria do frei franciscano Luca Pacioli, que surgem as primeiras ferramentas que serão utilizadas para facilitar o uso de sistemas de planejamento e controle, por meio dos dados produzidos pela Contabilidade.

Já no século XVI, surge o livro O Príncipe (Il Principe), escrito, em 1513, por Niccolò Machiavelli, que indicava a utilização do medo como meio de manter o controle sobre as pessoas, que para ele eram motivadas pelo interesse próprio. Pode ser mencionado também o livro A Riqueza das Nações (The Wealth of Nations), escrito por Adam Smith, em 1776, que defendia a ideia de uma organização eficiente por meio da especialização do trabalho. Como 
se pode perceber, embora relevantes, esses trabalhos abordavam temas distintos e não estavam diretamente relacionados à área de controle de gestão.

É a partir do início do século XX que começa a surgir uma série de trabalhos que procuram discutir de forma mais sistematizada os conceitos de planejamento e controle, por meio de enfoques fortemente relacionados às teorias econômica e das organizações. Entre os principais autores dessa época, podemos destacar: Frederick Taylor e Henry Fayol, considerados os pais da escola de administração científica; Elton Mayo, Mary Parker Follet, Chester Barnard, Max Weber, Rensis Likert e Chris Argyris que incorporaram os princípios da psicologia e sociologia à área de controle de gestão.

Para Fayol, existiam leis imutáveis que regiam os sistemas de controle: prever, organizar, mandar, coordenar e controlar eram atividades fundamentais para qualquer tipo de organização, àquela época, predominantemente empresas industriais. Fayol defendia a ideia da especialização da tarefa, a padronização das operações e a centralização como forma de se alcançar a eficiência administrativa. Para ele, controle era visto como uma verificação de que tudo estava correndo de acordo com o planejado. A estrutura organizacional funcional, com o organograma sob a forma de pirâmide, refletia os princípios da organização militar, bastante utilizada no início do século XX, que, durante muitos anos, foram adotados por um grande número de organizações (GOMES; AMAT, 2001).

Frederic Taylor (1947), em sua obra Administração Científica, procura utilizar as ideias de Fayol em experimentos práticos, passando a desenvolver seu quadro de referência teórico na Bethlehem Steel Company, nos Estados Unidos. Os principais pontos de suas ideias foram: introdução de incentivos financeiros e separação das tarefas de planejamento entre o responsável e o executor, supressão do individualismo e espontaneidade no trabalho, considerando os sentimentos do trabalhador como dados científicos.

Os trabalhos de Taylor e Fayol tiveram uma grande aceitação nos mais diversos tipos de organização que passaram a projetar sistemas de controle com características bastante rígidas e não levavam em consideração os aspectos motivacionais no comportamento das pessoas. Até hoje, em pleno século XXI, ainda podem ser encontrados exemplos de organizações que fundamentam seus sistemas de controle nas ideias oriundas da escola de administração científica, baseadas em normas e regulamentos rígidos, que procuram prescrever a forma ideal de gestão que é considerada válida para qualquer tipo de organização, independente de suas especificidades.

Para Hubel (1994, p. 19),

As pesquisas sobre motivação e o ambiente de trabalho da empresa eram ignorados pela administração empresarial clássica, em que a empresa se apresentava como uma máquina bem lubrificada e orientada em uma só direção através de uma trajetória maquinal e mecânica.

Ainda durante esse período surge outro autor famoso que estudou o controle sob a perspectiva do poder nas organizações. Max Weber, economista e sociólogo alemão, distinguia três tipos de poder: a autoridade carismática, o poder baseado em tradição e o poder burocrático. Para Weber, a burocracia, gerada por meio de um contrato jurídico, baseava-se na aceitação das normas legal-racionais que tinham como objetivo o alcance da eficiência. Essas ideias deram origem ao controle burocrático, ainda hoje bastante utilizado pelos órgãos públicos e por algumas empresas de grande porte. 
Em oposição a esses modelos racionais de controle, defendidos pelos autores da escola clássica de administração, Elton Mayo (1933), liderando uma equipe de pesquisa da Universidade de Harvard, realizou um estudo de campo na fábrica Hawthorne, da Western Eletric, em Chicago, com o objetivo de estudar as dificuldades relacionadas à produtividade no trabalho, em que predominavam sistemas de controle baseados nos fundamentos da escola clássica. Ele conseguiu refutar os conceitos de racionalidade, provando que os trabalhadores apresentavam um comportamento regido por outros valores e motivações, além das considerações de natureza essencialmente materiais. Essa pesquisa deu origem ao chamado Efeito Mayo, que proporcionou o surgimento, na década de 1960, da sociologia industrial.

Para Giglioni e Bedeian (1974), os principais autores que se preocuparam em construir quadros de referência sobre controle de gestão foram: Davis (1928), Glover e Maze (1937), Holden et al. (1941), Urwick (1943), Rowland (1947), Goetz (1949) e Dent (1935).

Em diversos momentos, o termo controle gerencial é tido como sinônimo de Contabilidade gerencial, controladoria e sistemas de informações gerenciais. Entretanto esses termos possuem significados distintos. Isso ocorre pela falta de consenso mundial sobre esses conceitos e pela sua utilização de forma desordenada nos trabalhos da área de Contabilidade gerencial, publicados nos principais periódicos internacionais (FERREIRA; OTLEY, 2005; JUNQUEIRA, 2010; CHENHAL, 2003, entre outros).

O controle gerencial compreende um grupo de atividades do processo de gestão, que, por sua vez, compreende também atividades de planejamento, escolha de um curso de ação por meio do desenvolvimento de objetivos e metas de curto e de longo prazos, e de execução, mobilização do pessoal e disponibilização dos recursos necessários para alcançar os resultados previstos (LUNKES; SCHNORRENBERGER, 2009). Dentre as atividades de um sistema de controle gerencial, destacam-se a coordenação, a comunicação, a avaliação, a tomada de decisão e o incentivo. Um modelo bem estruturado demonstra um grande potencial de colaboração com os gestores na formulação e na decisão de estratégias (CHANKAEW; USSAHAWANICHAKIT, 2011; SIMONS, 1990).

O controle de gestão inclui todos os arranjos organizacionais e as ações definidas para facilitar o alcance das metas de desempenho com o menor impacto de ações inesperadas (MAHAMA, 2006). Seguindo um tradicional conceito de controle, esse sistema fornece motivação e direcionamento para o cumprimento de objetivos, focando e corrigindo desvios dos padrões de desempenho (HENRI, 2006). Espera-se que todos os colaboradores e outras partes que se relacionem com a organização possam obter congruência entre seus objetivos pessoais e os objetivos organizacionais, adotando condutas que garantam uma boa reputação corporativa (SILVA; GOMES, 2008).

Pode-se avaliar o controle gerencial sobre diversas abordagens, como, por exemplo, a contingencial que analisará as variáveis como o tamanho da empresa, a tecnologia, o nível de concorrência existente, etc.; a de relação humana, enfatizando o grau de motivação e participação e de motivação gerado; a política, analisando as relações de poderes internas e externas; e a cultural que buscará identificar os valores e crenças gerados pelo sistema de controle. Para Gomes e Amat (2001), um sistema de controle não pode ser entendido somente pela perspectiva técnica. Sua avaliação deve ser feita mediante a avaliação do contexto estratégico e organizacional, enfatizando três elementos: sistema de controle, dividido em estrutura e processo de controle; contexto organizacional; e, contexto social. 
Quadro1- Vinculação do sistema de controle com o contexto social e organizacional

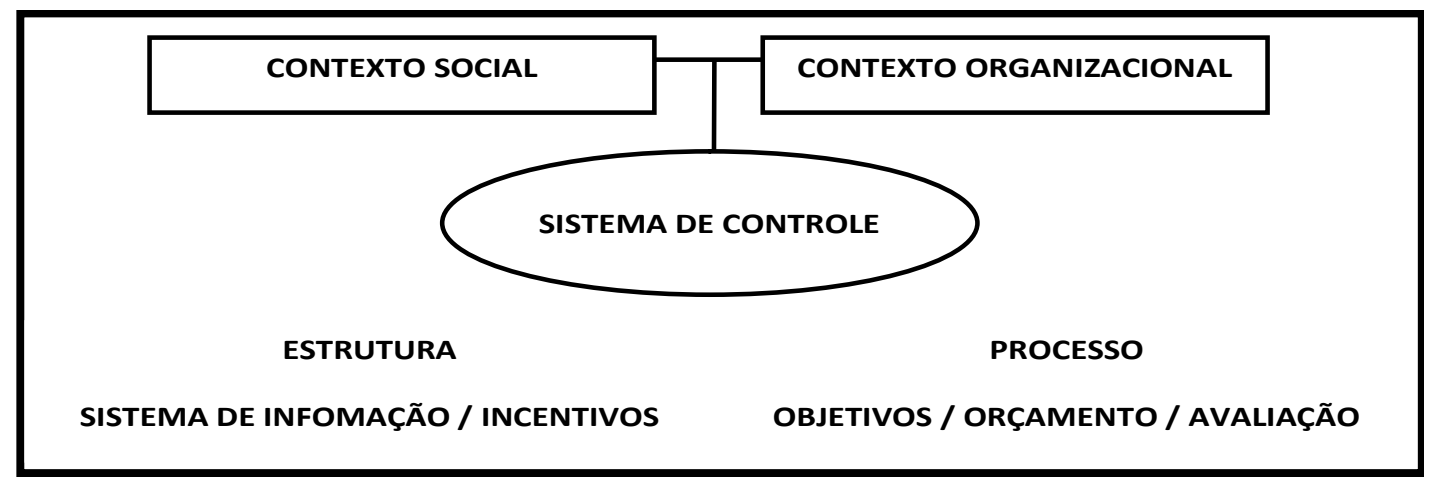

Fonte: Adaptado de Gomes e Amat (2001, p. 50).

$\mathrm{Na}$ estrutura de controle, destacam-se três elementos: sistema de medidas, sistema de incentivos e sistema de informação. Já no processo de controle, são enfatizados a definição dos objetivos, o processo orçamentário e a avaliação de desempenho.

\subsection{Contexto Organizacional e Social}

Conforme Pereira (2007, p. 5), "o contexto organizacional em que o sistema de controle opera, influencia fortemente o desenho e o funcionamento do sistema". Entre os fatores que exercem essa influência, tem-se a estrutura organizacional, a estratégia, as pessoas e as relações interpessoais da organização e a sua cultura organizacional.

Da mesma forma, o ambiente em que a organização está inserida, interno e externo, também apresenta impacto no sistema de controle gerencial de uma organização. Isso decorre da influência das partes interessadas e a necessidade de controle imposta por eles à organização (PEREIRA, 2007). Corroborando as informações anteriores, tem-se a teoria da contingência, construída "a partir da crença de que as organizações são influenciadas pelo ambiente e que a mudança ambiental é gradual, exigindo uma mudança organizacional concomitante" (JUNQUEIRA, 2010, p. 23).

Para Martinewski e Gomes (2001, p. 5),

os instrumentos e ações de controle, por sua vez, sofrem a influência de diversos aspectos que, quase sempre, não estão precisamente desenhados e determinados pela administração, tais como a cultura organizacional, o contexto social, entre outros. Tais influências devem ser consideradas quando se busca compreender o comportamento individual e organizacional.

Cruz, Scapens e Major (2011) estudaram os efeitos da relação entre a globalização e as influências sociais de um local específico, gerados a uma organização multinacional na instalação de uma nova unidade de negócio. Seus achados apontam a necessidade de adaptação do sistema de controle de gestão ao contexto em que determinada organização está inserida.

Assim, para a avaliação de um sistema de controle de gestão, devem-se avaliar, primeiro, as características da organização, como sua dimensão, a relação de propriedade, a cultura, o estilo dos gerentes e as relações interpessoais, o grau de descentralização e a formalização da atividade; e a avaliação de seu contexto social e ambiental, avaliando o grau 
de dinamismo e a concorrência. A partir desse conjunto de avaliação, apresentam-se quatro diferentes tipos de controle, conforme representado no Quadro 2:

\section{Quadro 2 - Tipologia de controle organizacional}

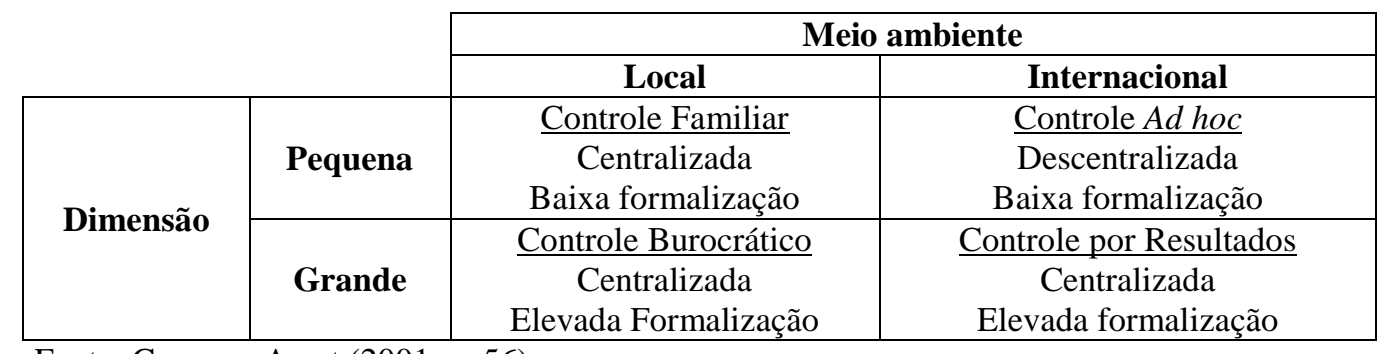

Fonte: Gomes e Amat (2001, p. 56).

No controle familiar, a característica do controle é informal e centrada em relações interpessoais de confiança e de lealdade. Normalmente, é encontrado em empresas de menor dimensão e de estabilidade ambiental, em que há uma liderança patriarcal e centralizadora das decisões. Ressalta-se que a denominação de familiar, nesse caso, trata-se do estilo de gestão e não ao fato de o capital da organização pertencer a uma família (SCHNEIDER; MORETTO NETO, 2006). Pode haver organizações com pessoas sem nenhum grau de parentesco, mas que tenham essas características de controle.

No controle burocrático, as principais medidas de controle são baseadas em medidas contábeis e financeiras, e a estrutura funcional é verticalizada, centralizadora e avessa a mudanças. É encontrado em empresas de grande porte não internacionalizadas que estejam em ambientes pouco competitivos.

Já no controle por resultados, encontram-se organizações em ambientes competitivos e com alto grau de descentralização por meio de centros de responsabilidades, aumentando, por consequência, a necessidade de controle. A ênfase ainda é nos indicadores financeiros, entretanto se diferencia do modelo burocrático pela adoção de um sistema mais abrangente com critérios de gestão e não apenas contábeis. Nesse modelo, há ligação entre os controles, as estratégias e os objetivos organizacionais e são encontrados planos de incentivos ligados à obtenção dos resultados.

Por fim, o controle ad hoc apresenta sua essência no autocontrole e se caracteriza por controles não formais. Está presente em organizações com estruturas descentralizadas e em ambientes muito dinâmicos e de grande complexidade. Normalmente compreende organizações em que suas atividades não são padronizadas e rotineiras, dificultando a utilização de medidas financeiras (GOMES; AMAT, 2001).

Conforme as organizações elevam seu nível de maturidade estratégica e sua percepção das incertezas do ambiente, o modelo de controle de gestão exercido também sofre alterações, melhorando seu desempenho. Kober, Ng e Paul (2003, p. 223) sugerem, por meio de seu estudo, "a existência de um modelo adequado entre sistema de controle de gestão e estratégia".

\subsection{Estrutura de Controle}


Como evidenciado no Quadro 2, a avaliação do sistema de controle de gestão deve ser realizado por meio da estrutura e dos processos definidos. Como elementos da estrutura de controle, destacam-se as medidas ou os indicadores adotados, a forma de incentivo aos colaboradores e o sistema de informação gerencial.

Para o controle da gestão e, consequentemente, para a avaliação de desempenho organizacional, faz-se necessário um conjunto de indicadores monetários e não monetários, estratégicos e operacionais (GOMES; AMAT, 2001; FREZATTI et al., 2009). Para Kaplan e Norton (1997, p. 32), "as medidas de resultado sem os vetores de desempenho não comunicam a maneira como os resultados são alcançados, além de não oferecerem uma indicação clara de que a estratégia esteja sendo implementada com sucesso ou não".

Os vetores de desempenho, mesmo oferecendo melhorias operacionais de curto prazo, mas sem interação com a avaliação do resultado, não permitirão aos gestores avaliar a relação causal com resultados com clientes e financeiros. Para uma escolha assertiva do conjunto de indicadores, deve-se analisar qual estratégia de diferenciação é preponderante na organização, evitando adoção de medidas incompatíveis com a estratégia, conforme relatos de Kaplan e Norton (2000, p. 101).

O controle gerencial e a avaliação de desempenho devem ser capazes de influenciar os indivíduos a alinharem seus objetivos pessoais com os objetivos organizacionais (MAHAMA, 2006). Entretanto, para obtenção dos resultados, estes devem permanecer motivados e suas necessidades pessoais atendidas. Assim, a organização deve oferecer recompensas ou retribuições adequadas de forma a influenciar a satisfação interna e incentivar mais dedicação e esforço pessoal no trabalho (LUNKES; SCHNORRENBERGER, 2009).

"Nesse sentido, a política de remuneração e recompensas da entidade deve estar atrelada a algum sistema de metas e recompensas." (FREZATTI et al., 2009, p. 158). "A remuneração por incentivos é poderosa alavanca para prender a atenção das pessoas aos objetivos da empresa e da unidade de negócios." (KAPLAN; NORTON, 2000, p. 269).

Uma opção é adoção de uma remuneração estratégica, buscando o aproveitamento das oportunidades para atingir taxas significativas de crescimento, recompensar desempenhos excepcionais, criar metas para as equipes de trabalho a partir dos objetivos estratégicos dos negócios, desenvolver funcionários no contexto do sistema de remuneração por habilidades e competências e atrair jovens empreendedores dispostos a assumir riscos (REIS NETO; MARQUES, 2004). Oyadomari et al. (2009), ao estudarem a influência da remuneração de executivos na congruência entre as metas organizacionais e pessoais, identificaram resultados que sugerem uma associação positiva entre a remuneração variável baseada em metas pessoais e o alcance das metas organizacionais. Os resultados apontam ainda a remuneração variável como um motivador ou incentivador monetário para a melhoria do desempenho, ao mesmo tempo que alertam para o risco do conflito de agência em organizações em que as metas pessoais não são associadas às metas globais. Faz-se necessário ressaltar que a adoção de um sistema de incentivo não compreende apenas aspectos de remuneração, mas pode ser utilizado também como critério de promoção interna ou outras formas de recompensa, evidenciando o mérito e contribuindo com a organização no longo prazo (FREZATTI et al., 2009).

O processo de gestão, em sua totalidade, deve ser assistido por um sistema de informação que forneça à entidade informações oportunas, corretas, confiáveis, tempestivas, compreensíveis, relevantes, entre outras características (CATELLI, 2001). Segundo Padoveze (2002), o sistema de informação é definido por um conjunto de recursos humanos, materiais, 
tecnológicos e financeiros agregados segundo uma sequência lógica para o processamento de dados que serão transformados em informações que, por sua vez, permitirão à organização o cumprimento de seus objetivos principais.

Já o subsistema de informação gerencial é aquele específico ao suporte das etapas do processo de gestão: planejamento, execução e controle. Este deve ser capaz de identificar os eventos a serem mensurados, bem como coletar, registrar e acumular os dados relativos a eles, processá-los, gerar a informação e comunicá-la com o intuito de orientar as ações dos gestores, motivando-os a tomar as melhores decisões (FREZATTI et al., 2009).

Além da Contabilidade, o SIG é alimentado basicamente por outros três subsistemas: Contabilidade, Custos e Orçamento. A Contabilidade registra todos os eventos econômicos que decorrem entre a organização e terceiros, bem como o efeito gerado por eles, como, por exemplo, as vendas e compras, e, por fim, os apresentam no formato de relatórios contábeis. As informações geradas pela Contabilidade são confrontadas por aquelas fornecidas pelo orçamento, como a projeção das metas. Nesse momento, há a comparabilidade entre o desempenho real e planejado. Por fim, o sistema de custeio é importante, pois fornece as informações conforme o critério adotado, como, por exemplo, por processos, atividades, centro de custos, entre outros (FREZATTI et al., 2009).

\subsection{Processo de Controle}

O processo de controle inicia com a adoção de objetivos e planos. O planejamento destaca-se pela sua antecedência a qualquer ação, esforço e gasto de recursos da organização; à sua natureza adaptável ao ambiente; à redução dos riscos e incertezas futuros que podem comprometer o cumprimento dos objetivos pré-estabelecidos; e à interação com as demais fases do processo de gestão, execução e controle, permitindo também a avaliação do desempenho organizacional (LUNKES; SCHNORRENBERGER, 2009).

Em todo o processo de planejamento, decisões de diferentes tipos e amplitude são demandadas aos gestores da organização. Estas são agrupadas genericamente por diversos autores em: decisões estratégicas, objetivos e resultados a serem atingidos no longo prazo; táticas, objetivos e metas de médio prazo e característica funcional; e operacionais, descrevendo a forma escolhida para o cumprimento deles (CATELLI et al., 2001; PELEIAS, 2002).

As características e diferenças do planejamento, bem como os objetivos e metas em cada nível, podem ser observadas no Quadro 3:

Quadro 3 - Características do planejamento estratégico, tático e operacional

\begin{tabular}{|c|c|c|c|}
\hline & \multicolumn{3}{|c|}{ Nível de Planejamento } \\
\hline & Estratégico & $\begin{array}{c}\text { Tático } \\
\end{array}$ & Operacional \\
\hline $\begin{array}{l}\text { Horizonte de } \\
\text { tempo }\end{array}$ & $\begin{array}{l}\text { Longo prazo } \\
\text { De cinco ou mais anos }\end{array}$ & $\begin{array}{l}\text { Médio prazo } \\
\text { De um a cinco anos }\end{array}$ & $\begin{array}{l}\text { Curto prazo } \\
\text { Geralmente de um ano ou } \\
\text { menos }\end{array}$ \\
\hline $\begin{array}{l}\text { Objetivos ou } \\
\text { metas }\end{array}$ & $\begin{array}{l}\text { - Qualitativos } \\
\text { - Potenciais de sucesso } \\
\text { - Parâmetros de lucro }\end{array}$ & $\begin{array}{l}\text { - Quali e quantitativos } \\
\text { - Objetivos de produto } \\
\text { - Capacidade de pagamento }\end{array}$ & $\begin{array}{l}\text { - Quantitativos } \\
\text { - Objetivos de vendas e } \\
\text { produção } \\
\text { - Lucro por produto }\end{array}$ \\
\hline
\end{tabular}




\begin{tabular}{|c|c|c|c|}
\hline $\begin{array}{l}\text { Variáveis e } \\
\text { alternativas }\end{array}$ & $\begin{array}{l}\text { - Estratégias para produtos e } \\
\text { marketing } \\
\text { - Atividade de negócio } \\
\text { - Posicionamento estratégico }\end{array}$ & $\begin{array}{l}\text { - Programa de produção } \\
\text { quanti e qualitativo } \\
\text { - Projetos de investimento e } \\
\text { programas de } \\
\text { financiamento } \\
\text { - Desenvolvimento de } \\
\text { pessoal }\end{array}$ & $\begin{array}{l}\text { - Planos de vendas, } \\
\text { produção, compra de } \\
\text { matérias-prima } \\
\text { - Planos de desenvolvimento } \\
\text { de atividades } \\
\text { - Planejamento da } \\
\text { capacidade de utilização de } \\
\text { pessoal }\end{array}$ \\
\hline $\begin{array}{c}\text { Características } \\
\text { específicas }\end{array}$ & $\begin{array}{l}\text { - Relativo à organização } \\
\text { como um todo } \\
\text { - Define para onde a } \\
\text { organização vai } \\
\text { - Avalia o ambiente } \\
\text { esperado } \\
\text { - Desenvolve estratégias } \\
\text { para alcançar os objetivos } \\
\text { pretendidos }\end{array}$ & $\begin{array}{l}\text { - Relativo à função } \\
\text { - Orienta o planejamento } \\
\text { operacional } \\
\text { - Avalia o desempenho dos } \\
\text { gerentes } \\
\text { - Define metas para alcançar } \\
\text { os objetivos pretendidos }\end{array}$ & $\begin{array}{l}\text { - Relativo à execução } \\
\text { - Define operações do dia-a- } \\
\text { dia } \\
\text { - Avalia o desempenho de } \\
\text { unidade de } \\
\text { responsabilidade específica } \\
\text { - Desenvolve metas visando } \\
\text { alcançar os objetivos } \\
\text { pretendidos }\end{array}$ \\
\hline
\end{tabular}

Fonte: Lunkes e Schnorrenberger (2009, p. 44).

Basicamente, no processo de planejamento, são definidos os objetivos organizacionais e as estratégias que serão adotadas para atingi-los. Com isso, cria-se o processo de interação entre o nível estratégico e os níveis táticos e operacionais, inicia a fase de execução e implementação do plano e, consequentemente, a fase de controle.

Um importante instrumento de controle consiste no orçamento que pode ser considerado versão quantitativa de um plano de ação construído com base no planejamento estratégico e operacional, já que possui, como uma das principais características, apresentar metas e resultados futuros mensuráveis a partir da projeção dos relatórios gerenciais atuais (PADOVEZE, 2004).

Kaplan e Norton (2004, p. 287) apresentam a importância do orçamento e a necessidade de integrá-lo com a estratégia organizacional:

\begin{abstract}
Achamos proveitoso raciocinar sobre cada um desses processos - gestão da estratégia e gestão das operações - como um loop autônomo de controle e aprendizado. Na gestão das operações, o orçamento atua como sistema de planejamento e controle. Ele define os recursos a serem alocados às operações das unidades de negócio no ano subsequente, assim como as metas de desempenho. Durante o ano, os gerentes analisam o desempenho das operações em comparação com o orçamento e adotam ações corretivas, quando necessárias.
\end{abstract}

O orçamento descreverá, principalmente, os recursos a serem gastos nas iniciativas e ações da organização, que, por sua vez, serão convertidos em resultados que retroalimentará o processo de planejamento e orçamento. Este é essencial para a fase de controle, bem como para a avaliação de desempenho, que permitirá à organização corrigir de forma tempestiva possíveis distorções entre o real e o planejado (OLIVEIRA; PEREZ Jr.; SILVA, 2004). Essa interação pode ser mais bem acompanhada na Figura 1. 
Figura 1 - Processo orçamentário

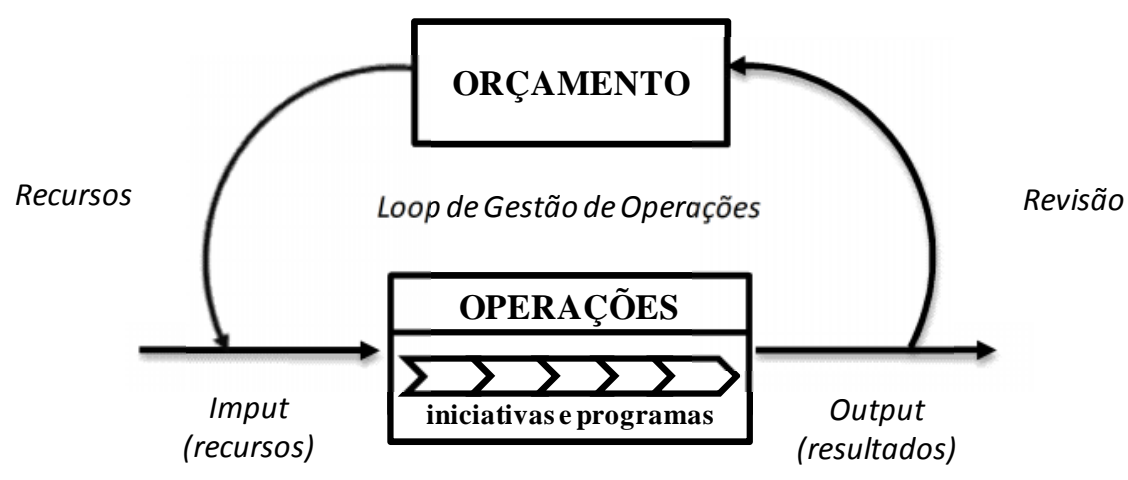

Fonte: Kaplan e Norton (2000, p. 288)

A eficiência e a eficácia do processo orçamentário dependem de alguns fatores. Entre eles destaca-se a orientação aos objetivos principais da organização; a participação efetiva e o comprometimento dos gestores; a comunicação e a mobilização de todos os colaboradores; a criação de metas realistas, ou seja, a organização deve encontrar o equilíbrio entre o desafio e o possível; o orçamento adaptável às mudanças de acordo com a demanda por elas; e a criação de políticas de incentivos, remuneração e reconhecimento (PADOVEZE, 2004).

King, Clarkson e Wallace (2010), em estudo realizado com gestores australianos sobre o uso do orçamento, demonstram a existência de uma relação positiva entre a utilização e a performance empresarial. O estudo evidencia ainda que o uso do orçamento se relaciona positivamente com uma estrutura organizacional descentralizada e com as estratégias empresarias.

Um eficiente modelo de gestão exige da organização meios que a permitam mensurar e avaliar o seu desempenho e resultados. Alguns autores afirmam que o que não pode ser medido, não pode ser gerenciado. Assim, a organização só terá meios de identificar se a sua missão está sendo cumprida ou não se a avaliação de desempenho compreender uma atividade de seu processo de gestão (SCHMIDT, 2002).

Para Ching (2006, p. 194), "o propósito da mensuração do desempenho é fornecer feedback sobre o andamento dos objetivos, medidas que oferecem um poderoso meio de impulsionar a melhoria". Por meio dessa atividade, é possível retroalimentar o processo de gestão, gerando um aprendizado organizacional que auxiliará na escolha das melhores estratégias a seguir.

Schmidt (2002) resume as principais razões para adoção de sistemas de avaliação de desempenho pelas organizações: controlar as atividades da empresa, estabelecer sistemas de incentivos aos colaboradores, controlar o planejamento, identificar problemas que necessitem intervenção dos gestores, e verificar se a missão da empresa está sendo atingida.

Borinelli (2006, p. 169) atribui à avaliação de desempenho a atividade de atribuir juízo de valor ao desempenho das funções, áreas organizacionais e seus respectivos gestores, a qual é estruturada logicamente segundo o seguinte processo:

(i) verificar o que se esperava das áreas, funções e gestores (identificação dos parâmetros); (ii) verificar o que, de fato, aconteceu (mensuração); (iii) observar quais são os parâmetros para qualificar o desempenho; (iv) analisar o desempenho, verificando, inclusive, causas de possíveis desvios; e (v) julgar o desempenho. 
Além da compreensão da necessidade de avaliação de desempenho, outro problema nesse processo é o esclarecimento do que se quer e deve medir. Nesse contexto, destaca-se a necessidade de relação entre o sistema de avaliação e as estratégias e metas previamente estabelecidas pela organização, já que estas fornecerão os padrões de comparação durante a fase de controle.

\section{Procedimentos Metodológicos}

Quanto aos procedimentos, o presente trabalho aborda a pesquisa bibliográfica de natureza teórica, evidenciando a visão dos principais trabalhos publicados na área e fundamentando o desenvolvimento do caso. Ainda sobre a perspectiva dos procedimentos, consiste também em um estudo de caso, o qual foi desenvolvido a partir de um protocolo previamente desenvolvido referente à empresa selecionada. $\mathrm{O}$ estudo de caso é utilizado para análise de conhecimentos contemporâneos, em que não há manipulação dos comportamentos relevantes (YIN, 2001).

Quanto à abordagem, a pesquisa é de natureza qualitativa, pois os fenômenos estudados na empresa objeto não permitem ser mensurados e devido ao fato de ter um formato que oferece análises mais profundas em relação a ele (BEUREN, 2006). Procurou-se realizar a técnica de análise de conteúdo para confrontar os resultados obtidos com o referencial teórico

Quanto ao método de coleta de dados, entre as técnicas que distinguem um estudo de caso, foram adotadas a observação direta e a série sistemática de entrevistas (YIN, 2001). As entrevistas realizadas foram do tipo semiestruturadas, o que permitiu aos autores realizar novos questionamentos no seu decorrer, conduzindo-as de forma espontânea. Essa técnica permitiu aos pesquisadores questionar os entrevistados sobre determinados fatos de seu interesse, oferecendo a eles a possibilidade de expressar opiniões e, em alguns casos, de também apresentar possíveis interpretações dos eventos (YIN, 2001).

Foram entrevistados o diretor, sócio da organização, e o contador, responsável pelo departamento financeiro. As razões para definição dos entrevistados foram o tempo de atuação na empresa e, especialmente, a ocupação de cargos que exercem a função ou as atividades relacionadas ao controle de gestão.

O uso da técnica de observação oferece ao pesquisador a possibilidade de incluir diretamente suas percepções sobre o objeto de estudo baseado em seus conhecimentos e em seus sentidos, aprimorando sua análise e diminuindo a subjetividade, já que consiste em mais um ponto de vista (BEUREN, 2006; GIL 2011). O modelo de observação adotado na pesquisa foi a observação participante ou ativa. Esse modelo consiste na participação real do conhecimento na vida do objeto de estudo, em que um dos pesquisadores assumiu o papel de membro do grupo, estando presente no interior da empresa estudada. Essa forma de coleta de dados possibilitou um rápido acesso aos dados sobre o atual sistema de controle de gestão da organização em todos seus aspectos (GIL, 2011).

Os dados foram analisados de forma qualitativa à luz da literatura, portanto foram apresentados de forma sintetizada, segmentada e caracterizada segundo componentes do estudo bibliográfico. As conclusões referem-se à comparação entre os conceitos discutidos 
sobre o sistema de controle de gestão e à prática encontrada na empresa objeto de estudo (GIL, 2011).

A pesquisa foi realizada no mês de fevereiro de 2012. Tendo em vista a não autorização para divulgação do nome verdadeiro da empresa, utilizou-se o nome fictício de HK Química. As limitações da pesquisa decorrem do método empregado, assim como a impossibilidade de se garantir a fidedignidade das respostas dos entrevistados.

\section{Descrição do Caso}

A empresa iniciou suas atividades em 1992 na cidade de Maringá, Paraná, e foi organizada por um ex-bancário com formação contábil que resolveu investir sua indenização trabalhista na constituição da empresa HK QUIMICA. De gestão familiar, é uma das pioneiras do setor químico na cidade e possui, atualmente, cerca de 30 colaboradores, além de seus representantes comerciais externos. Possui faturamento anual de aproximadamente seis milhões de reais, sendo classificada como pequena empresa conforme critérios do BNDES Banco Nacional do Desenvolvimento.

Nos últimos cinco anos, a empresa passou por um processo difícil devido a falhas de controle de gestão. A confiança do sistema de controle interno era centrada nas relações interpessoais, ou seja, o proprietário, detentor do poder, confiava nas pessoas que trabalhavam com ele, dispensando o uso de controles, medidas de desempenho e de tecnologias. Nesse período, foram enfrentados grandes problemas tributários e, consequentemente, problemas de liquidez.

Com o crescimento do número de empresas no setor químico que se instalaram ou passaram a atuar na região, aumentou a concorrência, expondo a deficiência do controle de gestão e intensificando as dificuldades financeiras, o que ocasionou corte de pessoal, redução de estoque e outras medidas. Em virtude desses fatores adversos, o gestor da empresa optou por segregar a organização para melhorar sua gestão e controle, conforme demonstra o organograma por unidade de negócio.

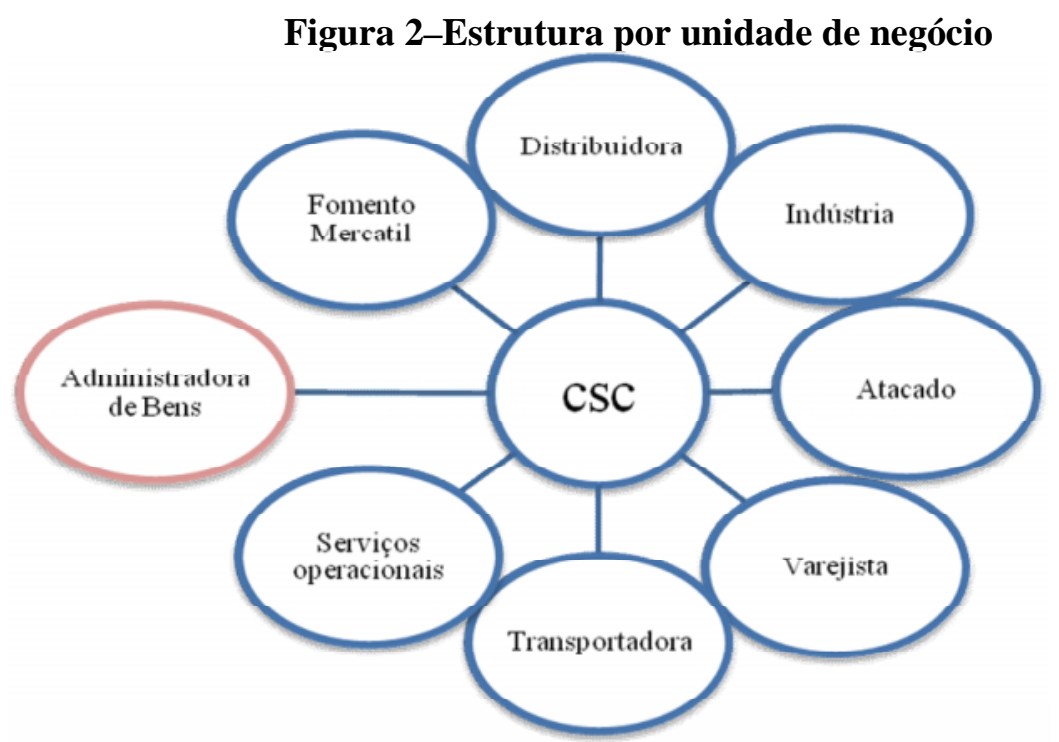

Fonte: Desenvolvido pelos autores 
Cada unidade de negócio criada passou a ter uma finalidade específica, atuando de forma sinérgica para melhoria do desempenho global da empresa. A distribuidora é responsável pela compra e estocagem de todos os produtos. Ela armazena as matérias-primas que são revendidas às demais unidades conforme requisição. Com isso, o gestor consegue controlar melhor seu estoque, comprar mercadorias em maior quantidade e repassá-las com melhor preço para as outras empresas.

A indústria, quando precisa de matéria-prima para fabricação de produtos acabados, faz um pedido à distribuidora, que é entregue pela transportadora mediante cobrança do frete da unidade requisitante. Esse sistema de entrega ofereceu um controle maior sobre a entrada e a saída de produtos. O sistema de produção é por ordem, dessa forma produz apenas o que está vendido.

A loja de atacado vende as cargas fechadas, ou seja, em maior quantidade, somente para empresas (pessoa jurídica) e mediante a análise de cadastro do cliente feita pelo setor financeiro. A loja varejista atende o consumidor final, vende em menor escala e utiliza ferramentas de publicidade e propaganda para anunciar, divulgar e expandir os negócios.

A transportadora atende à demanda interna e ainda realiza frete para terceiros, tendo uma frota com mais de 10 caminhões. A empresa prestadora de serviços operacionais realiza as atividades de envase dos produtos, carregamento dos caminhões e de higiene dos recipientes. O centro de serviço compartilhado é uma unidade de suporte às demais unidades de negócio, centralizando todas as atividades de caráter financeiro, recursos humanos, administrativo e relacionado ao sistema de gestão. A empresa de fomento foi criada no intuito de captar recursos bancários de uma maneira mais simples. Por fim, a administradora de bens possui a finalidade de preservar o patrimônio dos sócios.

A abertura dessas empresas tem justificativas distintas, sendo algumas, por fins estratégicos, para melhoria de desempenho e para fins de controle, tal como a transportadora, não dependendo mais de frete de terceiros, mas fazendo sua própria logística e de terceiros, e outras por fins tributários, aproveitando-se de alguns benefícios concedidos pela legislação, como a criação de uma empresa para setor atacadista e outra para setor varejista.

Com a abertura das unidades de negócio e a descentralização de atividades, a necessidade de controle da gestão tornou-se maior justificando a adoção de ferramentas tecnológicas que auxiliem nesse processo. Dessa forma, a empresa em questão optou pela aquisição de um software integrado de gestão (Enterprise Resource Planning - ERP) que passou a dar suporte às transações e operações das unidades sob o registro dos dados em apenas um banco de dados.

Do ponto de vista funcional, a empresa está organizada conforme representação na Figura 3. Mesmo com a criação de novas unidades e a descentralização das atividades, a tomada de decisão permaneceu centralizada no gestor principal, o sócio diretor. Este utiliza essencialmente as ferramentas financeira e orçamentária para tomada de decisão, e, para isso, contratou um profissional da área contábil e outro da área administrativa para auxiliar no processo de geração de informações. Esses profissionais atuam na unidade CSC - Centro de Serviços Compartilhados - onde apoiam e prestam suporte a todas as unidades de negócio, porém tendo as decisões vindas do gestor. O sócio administrador sempre atuou em todos os setores da empresa, onde, além de fazer o acompanhamento do processo produtivo, executa as compras e gerencia as vendas por intermédio de seus representantes. 


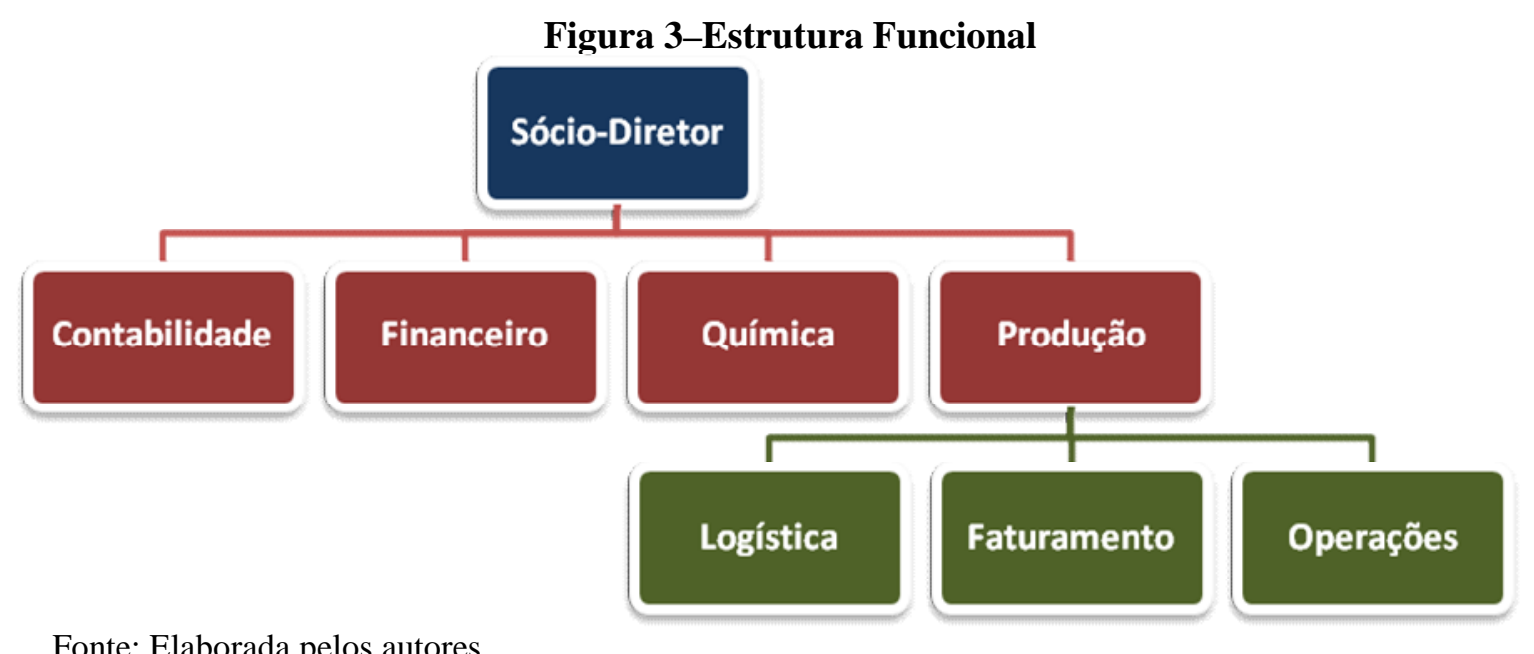

Fonte: Elaborada pelos autores.

Quanto à função de químico, este é exigido legalmente em virtude do ramo de negócio. Já o encarregado de produção é responsável pelo controle de gestão das unidades de logística, operação e faturamento, as quais são independentes como unidades de negócios, cada uma tendo seu controle interno.

Quanto à operação, as vendas são realizadas pelos representantes que fazem os orçamentos por meio de sistema que, quando aprovado pelo cliente, são encaminhados ao faturista, que registrará a venda e mandará uma ordem para a produção, iniciando o processo de envase, carregamento e distribuição do caminhão.

\subsection{Contexto organizacional e social da HK química}

Inicialmente, a organização iniciou suas atividades com um sistema de controle gerencial baseado no sistema de controle familiar, ou seja, o controle era baseado nas relações de confiança interpessoais e feito de forma informal. O processo de tomada de decisão era centralizado no principal gestor. Esse modelo é típico de empresas em fase de abertura que possuem uma dimensão ainda pequena.

Entretanto, devido ao crescimento da empresa e da quantidade de operações, o controle, até então existente, demonstrou ser ineficiente uma vez que as operações passaram a ser registradas legalmente de forma errônea, acarretando penalidades fiscais que comprometeram sua saúde financeira. Concomitantemente, empresas concorrentes se instalaram ou passaram a atuar no mercado de atuação da empresa em questão, ocasionando uma queda da fatia de mercado gradualmente e agravando ainda mais a situação financeira que já era ruim.

Dessa forma, o gestor principal observou a necessidade de mudanças no sistema de controle, migrando para um sistema de controle burocrático ainda de forma centralizadora, porém formalizada. Essa mudança se tornou ainda mais necessária a partir do momento em que houve a subdivisão da unidade principal em diversas unidades de negócios. A dimensão e a complexidade da organização aumentaram significativamente, justificando investimentos no sistema de controle, entre eles a criação de um setor de Contabilidade interna e a aquisição de um software integrado de gestão. 


\subsection{Estrutura de controle da HK química}

Foram destacados, na revisão da literatura, os elementos sistema de medidas, sistema de incentivos e sistema de informação como essenciais para eficácia da estrutura de controle organizacional. Os fatos descritos nos contextos organizacional e social da empresa a conduziram para um sistema de controle burocrático, trabalhando essencialmente com indicadores de características contábil e financeira. Os principais indicadores analisados são o nível de faturamento, os custos e as despesas realizadas, o resultado do exercício e o fluxo de caixa. A empresa não adota medidas de gestão não financeiras para sua avaliação de desempenho. A avaliação de eficiência da produção, por exemplo, devido ao sistema de produção por ordem, é avaliada apenas pela entrega dos pedidos de venda.

O sistema de controle não considera os aspectos motivacionais e não é utilizado como ferramenta de incentivo para obtenção dos objetivos organizacionais por parte dos colaboradores. Não há modelos de remuneração estratégica por resultados, refletindo uma estrutura centralizadora quanto ao poder decisório que não permite aos colaboradores participar ou tomar decisões, evidenciando ainda mais o modelo burocrático de controle. Não há medidas de desempenho e metas específicas para as funções, portanto os resultados são sempre avaliados de forma global.

Os indicadores financeiros são analisados por meio do sistema de informação gerencial. Este é parte do sistema de informação integrado (ERP) implantado na empresa que permitiu ao controle evoluir de planilhas eletrônicas para relatórios automatizados e instantâneos, cruzando variáveis pertinentes ao processo decisório. As informações geradas são pré-especificadas e seguem um padrão.

O sistema de informação gerencial reflete o sistema de medição utilizado pela empresa, ou seja, enfatiza apenas controles contábeis e financeiros e atende às necessidades informacionais apenas do principal gestor, que centraliza o processo de tomada de decisão. Não há presença de um sistema de apoio à decisão que permita simular cenários para uma tomada de decisão mais apurada e nem de um sistema de informação executivo que organiza as informações fundamentais para os gestores para um acesso de forma fácil, rápida e resumida.

\subsection{Processo de Controle da HK química}

No início das operações, com uma dimensão menor, a empresa efetuava seu controle por meio de diversas planilhas feitas no computador que não interagiam entre si e que precisavam ser alimentadas diariamente, de forma não automatizada. Com a criação de diversas unidades de negócios, para melhorar o controle de gestão, foi adquirido um sistema ERP, em que todas as informações estão integradas online. Sendo assim, todas as empresas são controladas pelo mesmo sistema.

O sistema ofereceu à empresa o registro de todos os eventos econômicos que decorrem entre a organização e terceiros, bem como o efeito gerado por eles, como, por exemplo, as vendas e compras, e, por fim, os apresentam no formato de relatórios.

No processo de controle, destacam-se na literatura as atividades de definição dos objetivos organizacionais, o processo orçamentário e a avaliação de desempenho. $\mathrm{O}$ planejamento e a formulação dos objetivos da empresa são feitos de forma centralizada, ou 
seja, pelo próprio gestor, que utiliza informações financeiras e contábeis para sua tomada de decisão concentrada no curto prazo. Na sua grande maioria, as decisões são tomadas de forma reativa aos fatos que assolam a organização, ou seja, não possuem um caráter preditivo característico da atividade de planejamento.

O planejamento de curto prazo e com poucas informações não é realizado de forma sistemática e é informal. Portanto a fase de alinhamento e de comunicação do plano é falha, ocasionando um desconhecimento dos colaboradores sobre as estratégias e sobre os interesses organizacionais. A empresa não avalia corretamente o ambiente interno e o externo, desconhecendo seus pontos fortes e fracos, deixando de aproveitar oportunidades e se expondo a possíveis riscos.

A quantificação dos planos, realizada por meio da técnica orçamentária, resume-se apenas em projeções e metas de vendas. As projeções são feitas com base em dados históricos e também de forma subjetiva por meio da experiência adquirida pelo sócio diretor. Portanto, fica notório que o orçamento como planejamento e controle de gestão não é utilizado pela empresa, que também não realiza planejamento estratégico formal.

Um eficiente modelo de gestão exige da organização meios que permitam mensurar e avaliar o seu desempenho e resultados conforme metas pré-estabelecidas na fase de planejamento e orçamento. A empresa HK QUIMICA não utiliza nenhum processo de avaliação de desempenho, sendo cada função controlada por seus encarregados apenas quanto ao cumprimento ou não das obrigações de cada colaborador.

\subsection{Análise dos resultados dos componentes do sistema de controle}

Diante das avaliações dos contextos organizacional e social e da estrutura e do processo de controle da empresa HK Química, destaca-se a presença de um modelo de controle organizacional burocrático, com a centralização do processo decisório e ênfase em medidas financeiras e contábeis. O Quadro 4 resume as principais constatações a respeito do sistema de controle de gestão avaliado na empresa objeto de estudo.

Quadro 4 - Análise dos componentes do sistema de controle

\begin{tabular}{|c|c|}
\hline \multicolumn{2}{|r|}{ ANÁLISE DOS COMPONENTES DO SISTEMA DE CONTROLE } \\
\hline $\begin{array}{l}\text { Contexto } \\
\text { Organizacional e } \\
\text { Social da HK } \\
\text { Química }\end{array}$ & $\begin{array}{l}\text { - Iniciou-se com o sistema de controle familiar } \\
\text { - Atualmente tem-se o sistema de controle burocrático. }\end{array}$ \\
\hline $\begin{array}{l}\text { Estrutura de Controle } \\
\text { da HK Química }\end{array}$ & $\begin{array}{l}\text { - Indicadores de característica contábil e financeira } \\
\text { - O sistema de controle não exerce a função motivacional e de incentivo } \\
\text { - Sistema de informação ERP }\end{array}$ \\
\hline $\begin{array}{l}\text { Processo de Controle } \\
\text { da HK Química }\end{array}$ & $\begin{array}{l}\text { - O Planejamento e a formulação dos objetivos da empresa são de curto prazo e a } \\
\text { tomada de decisão é centralizada } \\
\text { - Orçamento não como instrumento de planejamento futuro } \\
\text { - Avaliação de Desempenho inexistente }\end{array}$ \\
\hline
\end{tabular}

Fonte: Elaborado pelos autores. 
Percebe-se que o sistema de controle de gestão da HK Química não corresponde às características identificadas na revisão da literatura, uma vez que este não permite avaliar a performance da empresa e nem mobilizar os colaboradores e gestores para o cumprimento dos objetivos. Ao avaliar os elementos importantes para uma estrutura e um processo de controle na organização, nota-se um grande caminho a ser percorrido na busca por melhores práticas de gestão.

\section{Considerações Finais}

O presente trabalho objetivou analisar e avaliar à luz da literatura o sistema de controle de gestão de uma determinada empresa, considerada de pequeno forte, evidenciando os fatores predominantes de seu contexto social e organizacional que influenciaram na sua estrutura e processo de controle de gestão.

Com base nos dados coletados por meio de observação e entrevistas, constata-se que a organização estudada foi impactada diretamente por alterações no seu ambiente interno e externo, as quais contribuíram para a transição do sistema de controle familiar para o sistema de controle burocrático. O controle interno, inicialmente centrado na confiança das relações interpessoais, se mostrou frágil e ineficiente. Essa constatação se mostrou evidente no momento em que registros contábeis e de caráter tributários foram feitos de forma errônea ocasionando grandes passivos tributários e deficiências no caixa. O aumento da concorrência foi outro fato importe no contexto organizacional, expondo ainda mais as deficiências de gestão.

Esses fatos conduziram a empresa a um aumento na sua dimensão ao descentralizar suas atividades em diversas unidades organizacionais. Essa alteração pressionou uma melhoria dos controles refletida essencialmente na adoção de sistemas de tecnologia de informação que passaram a suportar as transações e dar suporte às decisões por meio de informações. Entretanto, a ênfase dos controles continuou fundamentada em medidas financeiras, típicas de um processo de gestão no modelo burocrático, não permitindo à organização planejar-se no longo prazo. Esse é um resultado que se distancia fortemente dos pontos relevantes vistos na literatura deste estudo sobre controle gerencial.

Apesar do aumento na dimensão da empresa em função da subdivisão em unidades de negócio e da descentralização das atividades, a tomada de decisão permaneceu centralizada no principal gestor. Portanto não há sistema de metas e de remuneração estratégica. O controle não exerce o papel de incentivo e de motivador à ação. Comparando a avaliação da HK Química com as características relacionadas com o referencial teórico, constata-se um afastamento significativo relativo às melhores práticas de gestão recomendadas pelos principais autores utilizados nesta pesquisa.

Por se tratar de um estudo de apenas um caso, sugere-se estudos posteriores comparar o sistema de controle gerencial aqui encontrado com os sistemas de outras empresas do mesmo setor, da mesma região ou do mesmo porte. Trabalhos, nesse sentido, contribuiriam para formar um perfil geral do sistema de controle de gestão para micro e pequenas empresas. Este trabalho não abordou aspectos relacionais entre as práticas de sistema de gestão e a performance empresarial, o que poderia ser explorado em futuros trabalhos. 


\section{Referências}

AGUIAR, Andson B. de; PACE, Eduardo S. U.; FREZATTI, Fábio. Análise do interrelacionamento das dimensões da estrutura de sistemas de controle gerencial: um estudo piloto. RAC-Eletrônica, Curitiba. v. 3, n. 1, p. 1-21, 2009.

ANTHONY, R. N.; GOVINDARAJAN, V. Sistemas de controle gerencial. 12. ed. São Paulo: McGraw-Hill, 2008.

BERRY, A. J.; COAD, A. F; HARRIS, E. P.; OTLEY, D. T.; STRINGER, C. Emerging themes in management control: A review of recent literature. The British Accounting Review, n. 41, p. 2-20, 2009.

BEUREN, Ilse Maria (coord.). Como elaborar trabalhos monográficos em Contabilidade: Teoria e prática. 3. ed. São Paulo: Atlas, 2006.

BORINELLI, Márcio Luiz. Estrutura conceitual básica de controladoria: Sistematização à luz da teoria e da práxis. 2006. 341f. Tese (doutorado). Departamento de Contabilidade e Atuária da Faculdade de Economia, Administração e Contabilidade da Universidade de São Paulo, São Paulo, 2006.

CATELLI, Armando (coord.). Controladoria: Uma abordagem da gestão econômica GECON. 2. ed. São Paulo: Atlas, 2001.

CHANKAEW, Nuntha; USSAHAWANITCHAKIT, Phapruke. Management control system and firm success: an empirical investigation of electronics parts businesses in Thailand. Journal of Academy of Business and Economics, v. 11, n. 4, p. 1-13, jun. 2011.

CHENHALL, R. H. Management control systems design within its organizational context: findings from contingency-based research and directions for the future. Accounting, Organizations and Society, v. 28, n. 2-3, p. 127-168, fev./abr. 2003.

CHING, Hong Yuh. Contabilidade Gerencial: novas práticas contábeis para a gestão de negócios. São Paulo: Prentice Hall, 2006.

CRUZ, Inês; SCAPENS; Robert W.; MAJOR, Maria. The localisation of a global management control system. Accounting, Organizations and Society, v. 36, p. 412-427, 2011.

DAVIS, R. C. The principles of factory organization and management. New York: Harper, 1928.

DENT, Arthur G. H. Management planning and control. London: Gee Ltd., 1935.

FERREIRA, A.; OTLEY, D. The design and use of management control systems: an extended framework for analysis. 2005. Disponível em: <http://dx.doi.org/10.2139/ssrn.682984> Acesso em: 20 fevereiro 2012.

FLORENTINO, Mauro Silva; GOMES, Josir Simeone. Controle gerencial em empresas brasileiras internacionalizadas: empresas do setor de serviços - o caso da SPOLETO. Contabilidade, Gestão e Governança, v. 12, n. 2, p. 24-34, mai./ago. 2009.

FREZATI, Fábio et al. Controle Gerencial: Uma abordagem da Contabilidade gerencial no contexto econômico, comportamental e sociólogo. São Paulo: Atlas, 2009. 
GIGLIONE, G. B.; BEDEIAN, A. G. A conspectus of management control theory: 19001972. Academy of Management Journal, v. 17, n.2, jun. 1974.

GIL, Antonio Carlos. Métodos e técnicas de pesquisa social. 6. ed. São Paulo: Atlas, 2011.

GLOVER, J. G.; MAZE, C. L. Managerial control. New York: Ronald, 1937.

GOETZ, B. E. Management planning and control. New York: McGraw-Hill, 1949.

GOMES, Josir S. \& AMAT SALAS, Joan M. Controle de gestão: uma abordagem contextual e organizacional. 3. ed. São Paulo: Atlas, 2001.

HENRI, Jean-François. Management control systems and strategy: a resource-based perspective. Accounting, Organizations and Society, v. 31, p. 529-558, 2006.

HERATH, S. K. A framework for management control research. Journal of Management Development. v. 26, n. 9, p. 895-915, 2007.

HOLDEN, P. E.; FISH, L. S.; SMITH, H. I. Top management organization and control. Stanford: Stanford University Press, 1941.

HUBEL, A. La gestión empresarial. Madri: Acento, 1994.

JUNQUEIRA, Emanuel Rodrigues. Perfil do sistema de controle gerencial sob a perspectiva da teoria contingencial. 2010. 156f. Tese (doutorado) - Departamento de Contabilidade e Atuária da Faculdade de Economia, Administração e Contabilidade da Universidade de São Paulo, São Paulo, 2010.

KAPLAN, S. R.; NORTON, D. P. A estratégia em ação: balanced scorecard. Tradução de Luiz Euclydes Trindade Frazão Filho. Rio de Janeiro: Elsevier, 1997.

KAPLAN, S. R.; NORTON, D.P. Mapas estratégicos: convertendo ativos intangíveis em resultados tangíveis. Tradução de Afonso Celso da Cunha. 8. ed. Rio de Janeiro: Elsevier, 2004.

KAPLAN, S. R.; NORTON, D.P. Organização orientada para a estratégia: como as empresas que adotam o balanced scorecard prosperam no novo ambiente de negócios. Tradução de Afonso Celso da Cunha Serra. 7. ed. Rio de Janeiro: Campus, 2000.

KING, Robyn; CLARKSON, Peter M.; WALLACE, Sandra. Budgeting practices and performance in small healthcare businesses. Management Accounting Research, v. 21, p. 40-55, 2010.

KOBER, Ralph; NG, Juliana; PAUL, Byron. Change in strategy and MCS: a match over time? Advances in Accounting, v. 20, p. 199-232, 2003.

LUNKES, Rogério João; SCHNORRENBERGER, Darci. Controladoria: Na coordenação dos sistemas de gestão. São Paulo: Atlas, 2009.

MAHAMA, Habib. Management control systems, cooperation and performance in strategic supply relationships: a survey in the mines. Management Accounting Research, v. 17, p. 315-339, 2006.

MARTINEWSKI, A. L; GOMES, J. S. Controle gerencial em empresas brasileiras Internacionalizadas: algumas evidências em empresas do setor de serviços. In: Encontro da ANPAD, 25, 2001, Campinas. Anais... ENANPAD, 2001. CD-ROM. 
MAYO, E. The human problems of an industrial civilization. Cambridge: Harvard University Press, 1933.

OLIVEIRA, Luís Martins de; PEREZ Jr., José Hernandez; SILVA, Carlos A. dos Santos. Controladoria estratégica. 2. ed. São Paulo: Atlas, 2004.

OYADOMARI, José C. T.; CESAR, Ana Maria R. V. C.; SOUZA, Eliane F. de; OLIVEIRA, Magda A. de. Influências da remuneração de executivos na congruência de metas. Revista Contemporânea de Contabilidade, v. 1, n. 12, p. 53-74, jan./jun. 2009.

OYADOMARI, José C. T.; FREZATTI, Fábio; MENDONÇA NETO; Octávio R.; CARDOSO, Ricardo L.; BIDO, Diógenes de S. Uso do sistema de controle gerencial e desempenho: um estudo em empresas brasileiras sob a perspectiva da resources-based view. REAd, v. 17, n. 2, p. 298-329, mai./jun. 2011.

PADOVEZE, Clóvis Luis. Sistemas de informações contábeis: Fundamentos e análise. 3. ed. São Paulo: Atlas, 2002.

PADOVEZE, Clóvis Luís. Controladoria básica. São Paulo: Thomson, 2004.

PELEIAS, Ivam Ricardo. Controladoria: Gestão eficaz utilizando padrões. São Paulo: Saraiva, 2002.

PEREIRA, Antonio José Patrocínio 2007. Características dos Sistemas de Controle Gerencial das Pequenas e Médias Empresas do setor farmacêutico do Estado do Rio de Janeiro: Estudo de Casos. ABCustos Associação Brasileira de Custos, v. 2, n.2, p. 1-21, mai/ago. 2007. Disponível em: <http://www.unisinos.br/abcustos/_pdf/AC-2007-69.pdf>. Acesso em: 20 fevereiro 2012.

REIS NETO, Mário Teixeira; MARQUES, Antônio Luiz. A remuneração variável e sua contribuição para a melhoria da gestão. Revista de negócios, Blumenau, v. 9, n. 1, p. 0517, jan./mar. 2004

RODRIGUES, Adriano; GOMES, Josir Simeone. Controle gerencial em empresas internacionalizadas: o caso da construtora Norberto Odebrecht S.A. Revista Contemporânea de Contabilidade, v. 1, n. 5, p. 15-96, jan./jun. 2006.

ROWLAND, F. H. Business planning and control. New York: Harper, 1947.

SCHMIDT, Paulo (coord.). Controladoria: Agregando valor para a empresa. São Paulo: Bookman, 2002.

SCHNEIDER, Christine; MORETTO NETO, Luis. Avaliação do desempenho organizacional da empresa familiar indústrias Alfa S.A. com base no modelo de gestão estratégica Balanced scorecard. Revista de Gestão USP, v. 13, n. 1, p. 89-104, jan./mar. 2006.

SEBRAE - Serviço Brasileiro de Apoio às Micro e Pequenas Empresas (org.). Anuário do trabalho na micro e pequena empresa: 2010-2011. 4. ed. Brasília: DIEESE, 2011. Disponível em: <http://www.sebrae.com.br/customizado/estudos-e-pesquisas >. Acesso em: $1^{\circ}$ dezembro 2012.

SILVA, Anderson Soares; FONSECA, Ana Carolina Pimentel Duarte. Controle gerencial por meio do benchmarking: o caso de uma organização de ciência e tecnologia da marinha do Brasil. Contabilidade Vista \& Revista, v. 20, n. 2, p. 65-98, abr./jun, 2009. 
SILVA, Vagner Guimarães da; GOMES, Josir Simeone. O uso do código de conduta ética como instrumento de controle gerencial: estudo de casos em empresas internacionalizadas. Revista Contemporânea de Contabilidade, v. 1, n. 10, p. 111-127, jul./dez. 2008.

SIMONS, R. The role of management control systems in creating competitive advantage: new perspectives. Accounting, Organizations and Society. v. 15, n. 1/2, p. 127-143, 1990.

TAYLOR, F. W. Scientific management. New York: Harper, 1947.

URWICK, L. F. The elements of administration. New York: Harper, 1943.

YIN, Robert K. Estudo de caso: planejamento e métodos. 2. ed. Porto Alegre: Bookman, 2001. 